\title{
Un error bíblico-dramático - ¿teológico-dramático? - en las teorías de Wardropper, Parker y Valbuena Prat sobre los autos sacramentales. Su influencia en las ediciones posteriores \\ A BiblicalDramatic (TheologicalDramatic?) Mistake in Wardropper's, Parker's and Valbuena Prat's Theories about «allegoric drama» (auto sacramental). Its Influence in further Publishings
}

Juan Manuel Villanueva Fernández

UNED

ESPAÑA

juan.manuel.villanueva@hotmail.com

[Hipogrifo, (issn: 2328-1308), 7.2, 2019, pp. 619-643]

Recibido: 10-09-2018 / Aceptado: 16-11-2018

DOI: http://dx.doi.org/10.13035/H.2019.07.02.46

Resumen. Para comprender en su exacto sentido los autos calderonianos, la primera tarea del crítico consiste en asegurarse de que ha comprendido las creencias de Calderón ${ }^{1}$ sin ser necesario compartirlas. En la primera mitad del siglo XX, dos corrientes literarias afrontan el estudio de los autos, siguiendo la doble hermenéutica proveniente del siglo XIX: el método histórico-crítico y la que exigía nuevos métodos siguiendo a los Padres de la Iglesia. Enunciaron ambas corrientes, respectivamente, Alexander A. Parker y Ludwig Pfandl. Soslayado y olvidado este último, la práctica unanimidad de estudiosos y editores ha seguido las directrices del gran estudioso inglés. Estas páginas desvelan, por una parte, algunas deficiencias

1. Parker, 1983, p. 36 
de su teoría: identidad argumento-asunto, errores teológicos de diversa gravedad, división de autos en dogmáticos-no dogmáticos, sacrificio único de Cristo; y, por otra, reclaman la necesidad de estudiarlos con suficiente perspectiva de teología católica, sobre todo con el ejemplo teórico y práctico de Pérez de Montalbán aplicando los cuatro sentidos con que se ha estudiado, y se estudia, la Sagrada Escritura. Básicamente se utilizan como argumentos mostrativos tres autos: Amar y ser amado, La divina Filotea, La hidalga del valle y Psiquis y Cupido.

Palabras clave. Autos sacramentales; deficiencias teoría Parker; argumentoasunto; taxonomía autos; teología católica; los cuatro sentidos bíblicos.

Abstract. In the first half of the $20^{\text {th }}$ century, two literary tendencies face the study of these plays, following the dual hermeneutics: the historicalcritic method and the one that demanded new methods according to the Fathers of the Church. Both trends were said, respectively, by Alexander A. Parker and Ludwig Pfandl. Placed obliquely and forgotten the last one, practically the unanimity of scholars and publishers has followed the guidelines of the English expert. These pages reveal, on one hand, some deficiencies in his theory: identity argument-matter (argumento/asunto), theological mistakes of varying seriousness, division of the Eucharistic pieces in dogmatists and not dogmatists: They all are «dogmatists», because they all dramatize the dogma of the Christ's only sacrifice: Eucharist Calvary; and, on the other hand, claim the need of study them with enough catholic theology perspective, especially with Pérez de Montalbán's theoretical and practical example applying the four senses with the ones he has studied, and still studies, the Holy Scriptures. Basically they are in use for arguing three pieces: Amar y ser amado, La divina Filotea, La hidalga del valle y Psiquis y Cupido.

Keywords. Autos sacramentales; Deficiency in Parker's Theory; Argument-Matter; Autos' taxonomy; Catholic Theology; Four biblical senses.

\section{Prolegómenos}

La comprensión plena de este trabajo presupone nuestra particular lectura de algunas ideas de Calderón, expuestas en dos trabajos precedentes².

Alexander A. Parker toma como base para estudiar los autos de Calderón el pensamiento de T. S. Eliot respecto a valorar la poesía de un poeta teniendo en cuenta su realidad vital como un todo, sin prescindir de sus intereses y creencias; de ahí que afirme:

Las ideas de los autos tienen, pues, que ser defendibles; no es necesario que se acepten. Pero, antes, es necesario que se comprendan, y la primera tarea del crítico consiste en asegurarse de que ha comprendido las creencias de Calderón, y de que se ha percatado de la relación que tienen con los hechos de la experiencia. Si estas creencias, o la forma en que se expresan, le son extrañas, entonces le 
hará falta proceder a un estudio atento paciente de las mismas, y, sobre todo, un sentir acorde que el prejuicio no haya hecho imposible. Las creencias de Calderón y la interpretación poética que les dio eran de auténtica realidad para él; también tienen que serlo para el crítico. Mientras no sea así, sus juicios no se asentarán sobre adecuada base y, probablemente, harán injusticia a la obra que está tratando de valorar ${ }^{3}$.

Como consecuencia de esto, Parker reconoce la superioridad de Valbuena Prat sobre la interpretación de Menéndez Pelayo respecto a los autos de Calderón; pero matiza:

Valbuena no consiguió basar su reivindicación de Calderón en un método analítico perspicaz o en una erudición sólida. [...] [Con su estudio y sus ediciones] consiguió que un público lector más amplio se fijara en ellos. Tras esto, Valbuena dirigió su atención hacia las comedias. Valbuena no fue más que un iniciador de estos estudios y no fue mucho más allá de la superficie de los autos. Su reivindicación de Calderón, en el marco más amplio de la nueva estima del barroco, se basaba en la idea del arte puro, concepto que nunca llegó a definir con claridad4 4

Pese al enriquecimiento y mejora que supone Parker respecto a Valbuena, es obligado analizarlo con las luces y sombras de su contexto histórico; y, en consecuencia, señalar su adscripción ${ }^{5}$ a uno de los planteamientos hermenéuticos bíblicos, diversificados desde el siglo XIX:

1) Defensores del método histórico-crítico: pretensión de comprender absolutamente un texto concreto aplicándole todo lo que permite aclararlo en su contexto histórico, lingüístico y cultural; no parece simplificación excesiva considerarlo actitud motriz de Parker indirectamente, también de Valbuena en sus análisis de los autos sacramentales.

2) Sin negar los excelentes e irrenunciables resultados del estudio diacrónico de la Biblia, otros exegetas ponen de relieve sus límites ${ }^{6}$ y recalcan la conveniencia

3. Parker, 1983, pp. 36-37.

4. Parker, 1983, pp. 37-38.

5. Cuestión distinta, en la que no es posible entrar, es si fue consciente de ello.

6. Ya en 1904, tras defender la necesidad inexcusable de la crítica literaria, H. Gunkel advertía, con la misma rotundidad, acerca de sus límites: «Otra cosa es saber si el desarrollo de esta crítica literaria, como es llevada actualmente a la práctica, corresponde con la finalidad de una recta exegesis. Me parece que se debe responder con un "no" resuelto [...]. Solo se han adquirido resultados ciertos en las grandes cuestiones, y no hay que hacerse demasiadas ilusiones: cuanto más desciende la investigación en el detalle, en las pequeñas unidades, tanto más inciertos se vuelven sus resultados. Las investigaciones de este tipo lo invaden todo. Pero no hay que consentirlo de ninguna manera. ¿Acaso habría que considerar normal que ciertos comentarios, incluso destinados al gran público, no se ocupen, aparte de la crítica textual, más que de crítica de las fuentes y de cuestiones históricas y arqueológicas, dejando de lado el aspecto religioso? [...] He aquí por qué no dejo de ponerme en guardia ante una sobreestimación de los problemas de crítica literaria. Y esta sobreestimación, temo, es la principal responsable del carácter mortecino de nuestra exegesis y de su fecundidad a los ojos de los agentes de pastoral; citado en La Sagrada Escritura en la Iglesia, 2015, p. 184 
y necesidad de operar, especificándolos, con nuevos métodos ${ }^{7}$, siguiendo las pautas de los Padres de la Iglesia, como recordaba aplicando el Concilio Vaticano II: Constitución dogmática Dei verbum sobre la divina revelación, Benedicto XVI en su Exhortación Verbum Domini:

Aunque obviamente no conocían los recursos de carácter filológico e histórico de que dispone la exegesis moderna, la tradición patrística y medieval sabía reconocer los diversos sentidos de la Escritura, comenzando por el literal, es decir, el significado por la palabras de la Escritura y descubierto por la exegesis que sigue las reglas de la justa interpretación [CIC, 116]. Santo Tomás de Aquino, por ejemplo, afirma: Todos los sentidos de la sagrada Escritura se basan en el sentido literal [Summa Theologiae, I, q. 1, a. 10, ad 1]. Pero se ha de recordar que en la época patrística y medieval cualquier forma de exegesis, también la literal, se hacía basándose en la fe y no había necesariamente distinción entre sentido literal y sentido espiritual. Se tenga en cuenta a este propósito el dístico clásico que representa la relación entre los diversos sentidos de la Escritura:

\section{Littera gesta docet, quid credas allegoria,} Moralis quid agas, quo tendas anagogia.

La letra enseña los hechos, la alegoría lo que se ha de creer, el sentido moral lo que hay que hacer y la anagogía hacia dónde se tiende [CIC, 118].

7. Benedicto XVI, en su Exhortación Verbum Domini, repitiendo ideas publicadas en 1989 y 2008, indicó: 35. A este propósito hay que señalar el grave riesgo de dualismo que hoy se produce al abordar las Sagradas Escrituras. En efecto, al distinguir los dos niveles mencionados del estudio de la Biblia, en modo alguno se pretende separarlos, ni contraponerlos, ni simplemente yuxtaponerlos. Estos se dan solo en reciprocidad. Lamentablemente, sucede más de una vez que una estéril separación entre ellos genera una separación entre exegesis y teología, que se produce incluso en los niveles académicos más elevados [Propositio 27] Quisiera recordar aquí las consecuencias más preocupantes que se han de evitar. a) Ante todo, si la actividad exegética se reduce únicamente al primer nivel, la Escritura misma se convierte solo en un texto del pasado: Se pueden extraer de él consecuencias morales, se puede aprender la historia, pero el libro como tal habla solo del pasado y la exegesis ya no es realmente teológica, sino que se convierte en pura historiografía, en historia de la literatura. [Intervención en la XIV Congregación General del Sínodo (14 octubre 2008): L'Osservatore Romano, ed. en lengua española (24 octubre 2008), 8; cf. Propositio 26] Está claro que con semejante reducción no se puede de ningún modo comprender el evento de la revelación de Dios mediante su Palabra que se nos transmite en la Tradición viva y en la Escritura. b) La falta de una hermenéutica de la fe con relación a la Escritura no se configura únicamente en los términos de una ausencia; es sustituida por otra hermenéutica, una hermenéutica secularizada, positivista, cuya clave fundamental es la convicción de que Dios no aparece en la historia humana. Según esta hermenéutica, cuando parece que hay un elemento divino, hay que explicarlo de otro modo y reducir todo al elemento humano. Por consiguiente, se proponen interpretaciones que niegan la historicidad de los elementos divinos [Cf. Ibíd.] Una postura como esta, no hace más que producir daño en la vida de la Iglesia, extendiendo la duda sobre los misterios fundamentales del cristianismo y su valor histórico como, por ejemplo, la institución de la Eucaristía y la resurrección de Cristo. Así se impone, de hecho, una hermenéutica filosófica que niega la posibilidad de la entrada y la presencia de Dios en la historia. La adopción de esta hermenéutica en los estudios teológicos introduce inevitablemente un grave dualismo entre la exegesis, que se apoya únicamente en el primer nivel, y la teología, que se deja a merced de una espiritualización del sentido de las Escrituras no respetuosa del carácter histórico de la revelación. 
Aquí observamos la unidad y la articulación entre sentido literal y sentido espiritual, el cual se subdivide a su vez en tres sentidos, que describen los contenidos de la fe, la moral y la tensión escatológica.

En definitiva, reconociendo el valor y la necesidad del método histórico-crítico aun con sus limitaciones, la exegesis patrística nos enseña que no se es fiel a la intención de los textos bíblicos, sino cuando se procura encontrar, en el corazón de su formulación, la realidad de fe que expresan, y se enlaza esta a la experiencia creyente de nuestro mundo.

Para el estudio de los autos sacramentales, esta segunda postura podría identificarse con el método seguido por Pfandl.

Debe quedar bien claro que el planteamiento de nuestro trabajo, sin embargo, no es la hermenéutica bíblica moderna. Se trata, más bien, de leer el teatro calderoniano, siglo XVII, en su contexto histórico y siguiendo las directrices explícitas que, como otros dramaturgos, por ejemplo, Juan Pérez de Montalbán, diferencia y aplica los sentidos bíblicos en sus autos.

Según se deduce de la crítica que Parker hace a Valbuena respecto a la interpretación de autos de la redención y de la Eucaristía, ambos autores coinciden en diferenciar ambos dogmas como totalmente distintos cuando, en realidad, se trata de la doble perspectiva del mismo sacrificio redentor de Cristo: cruento en el Calvario; incruento, en la Eucaristía. El Tesoro de Covarrubias ofrece la mejor comprensión, al diferenciar entre los sacerdotes de la Antigua y Nueva Alianza:

Sacerdote: El clérigo de misa [...] Los hebreos tuvieron sacerdotes que sacrificaban bueyes, corderos, etc. Eran figura de los sacerdotes de la Ley de gracia que ofrecen al Padre en sacrificio incruento del altar, el Cordero de Dios que quita los pecados del mundo.

Ante esta doble posibilidad hermenéutica, los hispanistas planifican su particular lectura y comprensión de los autos sacramentales. Para el alemán Pfandl:

Ya se indicó antes que el aspecto dogmático de los autos sacramentales no es únicamente la Eucaristía estrictamente hablado la que lo constituye. Este misterio de fe por su mismo asunto no hubiese sido suficientemente fecundo y variado. Por esto los poetas, con buen acuerdo, utilizaron el conjunto del dogma, y como que la solemnidad había de culminar en la glorificación de la Eucaristía, crearon dos clases de autos desde el punto de vista dogmático. En primer lugar los que se refieren inmediatamente a la Eucaristía, los cuales están por completo penetrados de ella y se concentran a su alrededor tanto en la acción como en los personajes. En segundo término, aquellos que sólo al terminar muestran, por medio de algún rodeo, su relación con la Eucaristía. Y no es sólo un mérito estético y artístico sino que también tiene su fundamento lógico que este rodeo no aparezca nunca mecánicamente zurcido ni traído de manera forzada. Porque ya indicamos que la Eucaristía no es sólo la conclusión y coronación de la obra redentora de Cristo sobre la tierra, sino por encima de todo el punto culminante de todo el dogma ${ }^{8}$. 
Por su parte, Alexander Parker, al enunciar su planteamiento teológico sobre los autos, lo hace con ciertas diferencias respecto al del estudioso alemán:

La Eucaristía, en cuanto Sacramento, da la vida sobrenatural de la Gracia. La lucha entre el bien y el mal, con todos sus variados aspectos, ofrece a los autos temas de importancia. La doctrina de la presencia real del cuerpo y sangre de Cristo, razón de la adoración eucarística, abre de par en par las puertas a todos los aspectos de la devoción católica, así como las de la hagiografía, los santos pueden presentarse como ejemplos de devoción perfecta. Calderón trata de todos estos aspectos del asunto. Todos sus temas tienen una relación estrecha, teológica o devota, con la Eucaristía de alguna de las maneras indicadas. Siguiendo estos criterios pueden clasificarse los autos en cinco grupos: (1) Dogmáticos, (2) de Historia Sagrada (histórico-teológicos), (3) Apologéticos9', (4) Morales, (5) de Devoción (hagiográficos). Ninguno de estos grupos necesita tener, ni mucho menos, un tema fijo, pero la amplitud del primer grupo es más limitada que la de los otros. La Eucaristía por sí sola no es, por tanto, el tema exclusivo de los autos (¿cómo podría haberlo sido?), pero es siempre su motivo ${ }^{10}$.

Hay, en esta última cita, ciertas imprecisiones teológicas. Desde el punto de vista sacramental, el comienzo enuncia una inexactitud o, más propiamente, un error: el sacramento primero que da la vida sobrenatural de la Gracia es el Bautismo; y, después, si se pierde la gracia bautismal por ofender gravemente a Dios, es el sacramento de la Penitencia el que la devuelve al cristiano arrepentido. La Eucaristía da vida, en el sentido de que enriquece la vida de la gracia, dada por el Bautismo o devuelta por la Penitencia (La hidalga del valle, vv. 1475-1486). Y, en cuanto a la división de los autos, para el hispanista alemán, existen dos clases respecto al dogma; para el inglés, frente a los dogmáticos, hay otros autos.

\section{PARKER Y LA IDENTIDAD ASUNTO-ARGUMENTO EN CALDERÓN}

Es muy grave el error de considerar unívocos cada uno de los términos argumento y fin en el fragmento siguiente, incluido por Calderón, en el primer (único) volumen publicado personalmente, de sus autos sacramentales:

A que se satisface, o se procura satisfacer, con que siendo siempre uno mismo el asunto es fuerza caminar a su fin con unos mismos medios, mayormente si se entra en consideración de que estos mismos medios, tantas veces repetidos, siempre van a diferente fin en su argumento ${ }^{11}$.

Tal univocidad ha dificultado la comprensión de aspectos esenciales de los autos sacramentales en las sucesivas ediciones. Escribe Parker (resaltamos nuestras observaciones):

9. Obsérvese que, en el mismo enunciado de este grupo, está implícito del valor argumental de las demostraciones, como se indica en el cuerpo del artículo.

10. Parker, 1983, pp. 49-50.

11. Calderón de la Barca, «Al lector. Anticipadas disculpas...», páginas preliminares a Autos sacramentales alegóricos y historiales. 
En el prefacio que puso a sus autos (del que hemos extraído las citas dadas en el capítulo precedente) Calderón distingue entre el asunto y el argumento del auto. El asunto que, nos dice, es siempre el mismo, necesitaba a menudo el uso de los mismos medios (personajes), pero estos medios siempre van a diferente fin en su argumento. Lozano, como hemos visto, ha señalado con especial elogio el hecho de que 1 os autos de Calderón fueran de tan diferentes argumentos. Hay, pues, en los autos identidad de asunto pero variedad de argumentos. En la medida en que nos ha sido posible discernirlo, estas dos palabras, incluso en la época de Calderón, no se usaban normalmente con sentidos diferentes [Una vez que el estudioso decide aplicar la segunda acepción del Tesoro de Covarrubias al término «argumento» parece obligada la aceptación de igual sentido]; a pesar de ello, nos parece que la distinción que establece nuestro autor entre ambas es clara. Por ejemplo, Otelo y El Mayor Monstruo los Celos son, a la vez, semejantes y distintos. Son semejantes en que aquello de que tratan son los celos, pero son distintos en que, a este asunto, se le da diferente forma en el tema y en el argumento de las obras. Son semejantes en el asunto pero distintos en el argumento. El asunto de todo auto es, pues, la Eucaristía, pero el argumento puede variar de uno a otro puede proceder de cualquier historia divina histórica, legendaria o ficticia con tal de que ilumine de algún modo un aspecto del asunto [Obsérvese que, con esta afirmación, casi inconscientemente, el hispanista se inclina por la primera acepción del Tesoro] $]^{12}$.

Puesto que en este fragmento se fundamenta la teoría del hispanista sobre los autos sacramentales de Calderón, parece obligado comentarlo con detalle: validarlo implica justificar su división de los autos sacramentales implícitamente, también la de Valbuena Prat, seguida por la generalidad de los estudiosos; por el contrario, su rechazo las deja sin sentido, es decir, las inutiliza. Volveremos sobre esto.

Trataremos de demostrar que todo el fragmento es un error múltiple. Conociendo la honradez del sabio hispanista, sería radicalmente injusto calificarlo de gran engaño. Dejando para más adelante las dos primeras afirmaciones a las palabras de Calderón, enunciamos estos errores:

- Primero. En la medida en que nos ha sido posible discernirlo, estas dos palabras, incluso en la época de Calderón, no se usaban normalmente con sentidos diferentes.

- Segundo. A pesar de ello, nos parece que la distinción que establece nuestro autor entre ambas es clara. Por ejemplo, Otelo y El mayor monstruo los celos son, a la vez, semejantes y distintos. Son semejantes en que aquello de que tratan son los celos, pero son distintos en que, a este asunto, se le da diferente forma en el tema y en el argumento de las obras. Son semejantes en el asunto pero distintos en el argumento.

-Tercero. La identificación argumento-asunto en el fragmento de Calderón implica una contradictio in terminis. 
Resulta asombroso, respecto al primero, comprobar que, sin plantearse la menor duda, todos los investigadores han manifestado implícita y/o explícitamente estar conformes con identificar asunto=argumento. En cambio, lo primero que nos cuestionamos nosotros es: ¿cómo no le fue posible encontrar un significado, un sentido diferente al término argumento? Tamaña afirmación nos resulta asombrosa teórica y prácticamente. De forma teórica, todos los diccionarios de la época, incluyendo los bilingües, comienzan sus definiciones - cuando no la limitan a ellapor la primera acepción del Tesoro, de Sebastián de Covarrubias, también la primera de Autoridades:

Argumento: la cuestión o contrario que le pone, o el que uno hace para probar su intento, porque, como dice Quintiliano: Argumentum est ratio, probationem praestans, qua colligitur aliud per aliud et quae, quod est dubium, per id quo dubium non est confirmat. Otras veces sinifica la materia de que trata alguna cosa que llamamos hipótesis, del nombre griego uாî日eఠıs, suppositio, como los argumentos de las comedias y de cualquier obra; y también sinifica el tema y el propósito de algún discurso (Cov). La razón con que se impugna la sentencia, u opinión de otro, dispuesta artificiosamente según las leyes de la Dialéctica. Es voz de las Escuelas que se difunde a todas las ciencias, y puramente latina. Lat. Argumentum. Ratio. / Algunas veces se toma por el que arguye, y así se dice: Fulano es gran argumento. / Llámase así también el asunto o materia de que habla algún libro: como argumento de la llíada, de la Eneida (Aut).

Para la demostración práctica dramática, véase el apartado dedicado a La divina Filotea.

En cuanto al segundo, debe observarse bien que el asunto de Otelo y de El mayor monstruo los celos, no son los celos, sino la tragedia de los celos. Los celos son un tema que se proyecta en una doble o, mejor, triple dirección: tragedia, comedia y comedia burlesca. Una vez que el dramaturgo se decide por la tragedia, elige los argumentos que satisfacen su asunto: por supuesto, distintos en el caso de Otelo, la terrible y malvada manipulación de Yago, y de El mayor monstruo los celos, el progresivo autoconvencimiento del desgraciado, y también perverso, protagonista.

Si son graves los dos primeros puntos, mucho más lo es ${ }^{13}$ que tal identificación implica acusar a Calderón de una doble afirmación contradictoria en sus términos. Comprobémoslo:

1) Siendo siempre uno mismo el asunto es fuerza caminar a su fin con unos mismos medios; es decir: se requieren los mismos medios para conseguir el fin de un mismo asunto.

13. Para recalcar esta gravedad, debe tenerse presente que Parker -seguido por incontables estudiosos - ha denominado a Calderón «dramaturgo de la Escolástica». Tal aserto contradice de plano, como hemos señalado en otras ocasiones (Villanueva, 2013), la rotunda afirmación de su primer «aprobador», el Maestro Lozano: «la solidez en las dos teologías escolástica y expositiva»; flaco favor se le hace al gran creador de autos sacramentales, con aprovechamiento de los cuatro sentidos bíblicos, reduciendo su horizonte teológico a la escolástica. 
2) Por el contrario, estos mismos medios, tantas veces repetidos, siempre van a diferente fin en su argumento; si no lo entendemos mal, significa lo contrario de lo dicho en la afirmación primera, puesto que asegura, si los términos son sinónimos, que utiliza los mismos medios para conseguir diferente fin en el mismo asunto.

\section{AUTO CONTRARIO A LA IDENTIFICACIÓN DE PARKER ARGUMENTO=ASUNTO: LA DIVINA FILOTEA}

Amar y ser amado, la divina Filotea es ejemplo práctico de su no igualdad, pues contiene nueve veces el término argumento y ninguna de ellas con el sentido de asunto. Citémoslos brevemente:

MUNDO El apóstata que todo es cuestiones y argumentos ni creyendo ni dudando siempre dudando y creyendo con su ingenio mal hallado (jay de al que daña su ingenio!) también con su gente llega buscando, a lo que yo pienso, entre tantos ritos varios si encuentra en alguno de ellos quien siga sus opiniones (vv. 702-712).

APOSTASÍA ... quisiera aliviar contigo las que conmigo padezco acerca de no sé qué inescrutables misterios que quiere que crea la letra de profetizados versos, mayormente los de un pan vivo que bajó del cielo y pan de ángeles en él es en la tierra alimento del hombre; en cuyo sentido hacerte capaz pretendo, ya que te hallé, para que oídos mis argumentos, mis dogmas, mis opiniones, veas la razón que tengo.

ENTENDIMIENTO Para tan alta materia ni esta es ocasión ni es tiempo (vv. 844-861).

Apostasía Quedamos, si bien te acuerdas, que en las dudas que padezco acerca de un vivo pan que yo ni alcanzo ni entiendo pretendía consultarte 


\begin{tabular}{|c|c|}
\hline ENTENDIMIENTO & $\begin{array}{l}\text { para que con tu consejo } \\
\text { eligiese lo mejor. } \\
\text { Por entonces no hubo tiempo, } \\
\text { conque dejando pendiente } \\
\text { la razón de mi argumento } \\
\text { salimos a la campaña. } \\
\text { Ya está de más todo eso. } \\
\text { Aparte. Retirámonos vencidos (vv. 1521-1533). }\end{array}$ \\
\hline Apostasía & $\begin{array}{l}\quad \text { Pues porque } \\
\text { veas que le es dado, siendo } \\
\text { incomprensible, no darle } \\
\text { crédito ninguno, intento } \\
\text { a las escuelas dejando } \\
\text { los lógicos argumentos } \\
\text { convencerte con la real } \\
\text { prueba de un práctico ejemplo. } \\
\text { Los sentidos van pasando, } \\
\text { como dije, conduciendo } \\
\text { desde la nave al castillo } \\
\text { el pan de su bastimento. } \\
\text { Lleguemos a ellos, pues no } \\
\text { es posible conocernos, } \\
\text { que a los sentidos no toca } \\
\text { conocer entendimientos; } \\
\text { y como con una voz } \\
\text { sola te arguyan, no quiero } \\
\text { tener de ti más victoria } \\
\text { que verte concluido de ellos (vv. 1567-1586). }\end{array}$ \\
\hline APOSTASÍA & $\begin{array}{l}\text { Espiga que en la erial } \\
\text { tierra donde te sembraste } \\
\text { con la sangre te regaste } \\
\text { de tu mismo mayoral: } \\
\text { palabra fuiste inmortal, } \\
\text { pero a creer no me ajusto } \\
\text { que aquí lo eres, que no es justo } \\
\text { contrato ni creer espero } \\
\text { lo que otro dice primero } \\
\text { que lo que yo mismo gusto. } \\
\text { ¿Qué dirás ahora? }\end{array}$ \\
\hline ENTENDIMIENTO & $\begin{array}{l}\text { Que intento } \\
\text { en vano responder bien, } \\
\text { que en llegando a esto también } \\
\text { se pasma el Entendimiento. } \\
\text { Poderoso es tu argumento, } \\
\text { pero oigamos al Oído (vv. 1633-1648). }\end{array}$ \\
\hline
\end{tabular}


ENTENDIMIENTO Eso fuera bueno cuando la fuerza de su argumento no me hubiera convencido.

FE Según eso ya no tengo para qué seguirle a él si en ti su cómplice encuentro. Saque contra ti la espada que para él empuñé (vv. 1713-1720).

ENTENDIMIENTO Sí, pero ¿quién será ese para el propósito nuestro con tantas señas de Dios?

FE En propiedad nadie, pero en similitud aquese embozado aventurero que Príncipe de la Luz, en sombras de blanco velo enamorado del alma viene a librarla en su riesgo. Mira ahora si podrás excusar, Entendimiento, la herida de conclusión, pues en la fuerza del duelo contra los sentidos es de Gregorio el argumento.

ENTENDIMIENTO Con todo eso, todavía yo lo dudo. Sale Oído.

Oíno Yo lo creo (vv. 1783-1800).

Todos ¿Qué velo será?

NIÑO Descúbrese un altar con Hostia y Cáliz, y allí junto un Niño Este blanco pan que descendió del cielo en que mi carne y mi sangre fue de tu socorro el precio. A él se postrará rendido por la Fe el Entendimiento, por amor la Caridad,

la Esperanza por el premio; la Apostasía vencida de todos sus argumentos, la Gentilidad postrada, y el espíritu soberbio del Príncipe de Tinieblas le adorará a su despecho, corregida la Lascivia, $y$ todos juntos diciendo: 


$\begin{array}{ll}\text { Todos } & \text { A tan alto sacramento } \\ & \text { venere el Mundo rendido, } \\ & \text { pues es último argumento } \\ & \text { que la Fe por el Oído } \\ & \text { cautivó al Entendimiento (vv. 1961-1981)14. }\end{array}$

Curioso resulta comprobar que la última cita, precisamente en los versos que cierran el auto Amar y ser amado, La divina Filotea, traducción parcial del Tantum ergo - estrofas finales del himno Pange, lingua, de santo Tomás de Aquino- es la síntesis de los anteriores. ¿Por qué?

Para comprenderlo, aprovecharemos un fragmento de nuestra reseña al espléndido libro de Juan Belda Plans, La Escuela de Salamanca:

A Domingo de Soto corresponde una valoración extraordinaria de la diferencia entre practicar la fe y fundamentar racionalmente la validez de sus principios. Esta argumentación la detalla en su valoración de la Teología como ciencia. Del máximo interés es su reflexión y valoración sobre si es argumentativa, llegando a tres conclusiones:

1) La teología no demuestra sus principios; simplemente, a partir de ellos, deduce, demuestra otras verdades.

2) No es posible argumentar contra los infieles porque no creen en las Sagradas Escrituras, pero sí contra los herejes. A estos, con argumentación basada en la Sagrada Escritura, en la que ellos creen parcialmente, se debe razonar y argumentar.

3) Si no se puede argumentar contra los infieles, sí es posible responder a sus argumentos, demostrando que son falsos los suyos.

14. En este auto también participa Ateísmo, el único a quien directamente se impide, sin diálogo desde que se presenta como sin Dios, la entrada a la ciudad; incluso Fe lo amenaza de muerte. Es con el único, repetimos, que no se discute, frente a otros autos en los que la discusión con Ateísmo alcanza el protagonismo. Los demás personajes exponen diversos argumentos en defensa de sus posturas. Alcance especial tienen, como es de suponer, las referidas al Santísimo Sacramento, cuestión primordial entre Apostasía y Entendimiento. No es de extrañar, pues, que así concluya el auto (vv. 1931-1981)

Aclaración a los vv. 1941-1948:

PRínCIPE No te espantes,

porque aún no ha llegado el tiempo.

FE Perdona, que sí ha llegado.

PRÍNCIPE ¿Cómo?

FE Corriéndote el velo.

la Fe, que sin verte ve

tu divino ser inmenso

cuando la contemplación

la arrebata el pensamiento.

v. 1948: Como Calderón era laísta, entendemos que, en este verso, lo que la Fe dice es que, cuando, en arrebato místico, alcanza su culmen la contemplación, esta le arrebata el pensamiento, con lo que queda libre para la visión directa del Amado. 
Y señala Belda:

En otros términos, podemos aducir algunas razones que, aunque no sean demostrativas, al menos sean probables y congruentes con la verdad, dado que para nosotros es claro que las proposiciones que se ponen contra la fe no son demostrables, ni pueden concluir nada contra la fe, puesto que la fe es verdadera y no puede estar a la base de ningún error. Pero una cosa es saber que todos los argumentos contra la fe son solubles y otra distinta saber resolverlos. Todos los cristianos, en efecto, saben bien que son rebatibles, porque creen que los artículos de la fe han sido revelados por Dios, y en consecuencia que no pueden ser falsos; pero, sin embargo, no saben contestar todos los argumentos contrarios. En tal sentido se afirma que la teología es argumentativa; a ella corresponde solucionar los argumentos contrarios a la fe y mostrar cómo y por qué son falsos ${ }^{15}$

Cada uno de estos nueve fragmentos de La divina Filotea va desgranando un argumento distinto, en pro de la demostración sacramental de la Eucaristía que, por la transubstanciación, contiene la presencia real del Cuerpo y la Sangre de Cristo bajo las especies de pan y vino ${ }^{16}$.

15. Belda, 2000, pp. 451-452

16. Su desarrollo exigiría exponer nuestra particular lectura de las definiciones de auto y auto sacramental en Lope de Vega, Covarrubias y Calderón de la Barca. También el alcance de los términos alegoría y alegórico en los autos calderonianos, en conexión con la aplicación de los cuatro sentidos bíblicos con que la Iglesia lee la Sagrada Escritura, desde san Pablo hasta la actualidad, incluyendo su gran importancia durante el Siglo de Oro español, en todos los géneros literarios, pero de forma muy especial en el teatro $y$, dentro de este, en los autos. Remitimos a nuestro trabajo de Pamplona. 
Sintetizando, pues, establecemos, en el teatro calderoniano, tres acepciones al término argumento: razón filosófica; materia de que trata una obra ${ }^{17}$; imposición irracional ${ }^{18}$.

\section{DOGMA: CRUZ, SACRIFICIO CRUENTO; MISA, INCRUENTO}

Es preciso comenzar proclamando que, en esencia, los autos sacramentales -y de forma muy especial, los de Calderón- más que contener, son teología; para su

17. Ahondando la cuestión léxica del término 'argumento' en Calderón, en esta segunda acepción «la materia de que trata alguna cosa» hallamos un caso concreto, de cuya trascendencia, que sepamos, ningún estudioso ha llamado la atención:

$\begin{array}{ll}\text { PLACER } & \text { A ti te está muy bien eso, } \\ & \text { que al fin vives con los más. } \\ & \text { Yo, que vivo con los menos, } \\ & \text { ¿qué mucho, siendo el Placer } \\ & \text { me retire, y más teniendo, } \\ & \text { para estar suspenso, causa? } \\ \text { PESAR } \quad \text { ¿Qué causa? } \\ \text { PLACER } \quad \text { No hallar, mi ingenio, } \\ \text { al ver que ya restaurado } \\ \text { deja, el rey, al mundo entero } \\ \text { y, al hombre, por virrey suyo, } \\ \text { con todos sus sacramentos, } \\ \text { de qué ha de ser este auto, } \\ \text { puesto que empezar le veo } \\ \text { por donde acaban los otros. } \\ \text { ¿Eso te entristece, necio? } \\ \text { Pues ¿qué me ha de entristecer } \\ \text { sino ver un argumento } \\ \text { vuelto lo de abajo arriba? } \\ \text { ¿No estaba en estilo puesto } \\ \text { que empiece el hombre pecando, } \\ \text { que acabe Dios redimiendo, } \\ \text { y en llegando el Pan y el Vino } \\ \text { subirse con él al cielo, } \\ \text { al son de las chirimías? } \\ \text { Pues ¿cómo hoy no pasa eso? } \\ \text { ¿Es mozárabe este auto? } \\ \text { (Lo que va del hombre a Dios, vv. 438-463). }\end{array}$

Si nuestra lectura es correcta, la afirmación contradice la opinión generalizada de la diferencia radical, enunciada por Wardropper, entre los autos de Valdivielso y los de Calderón. Ver Villanueva, 2008.

18. Tampoco se acaba con esta segunda acepción la riqueza del término 'argumento' en Calderón, pues, por ejemplo, lejos del argumento racional, también, por boca de un gentil-enemigo de Israel, le atribuye el significado-acepción de 'fuerza bruta'. Dice Goliat: «Contra todo ese aparato / de sombras, luces, bosquejos, / rasgos, visos y figuras, / antes que yo llegue a verlos / acabaré con vosotros / retándoos a campal duelo, / con ley de que el que venciere / (que es el más fuerte argumento / de que fuese Goliat / caudillo del filisteo, / pues no pudiera dar ley / el que no llegara a serlo), / con ley, digo, de que aquel / que venciere cuerpo a cuerpo / lleve el pueblo del vencido / esclavo del otro pueblo» (El arca de Dios cautiva, vv. 1764-1779). Pero no es un tema en el que debamos entrar en este momento. 
comprensión no basta con señalar las fuentes bíblicas y/o patrísticas, etc. aprovechadas; es preciso explicar por qué el dramaturgo ha elegido esas y no otras, y cómo influyen en la estructura dramática y visión eucarística del auto.

Fue Calderón quien definió el auto sacramental así:

PASTOR

\section{Sermones}

puestos en verso, en idea

representable, cuestiones

de la Sacra Teología

que no alcanzan mis razones

a explicar ni comprender,

y el regocijo dispone

en aplauso de este día ${ }^{19}$

Para comprender el alcance de este «sentido teológico» se hace preciso volver al Tesoro, de Sebastián de Covarrubias, en el término misa.

Con la perspectiva temática utilizada para su taxonomía de los autos (ver «Prolegómenos»), el ilustre hispanista realiza la susodicha división entre autos dogmáticos y autos no dogmáticos, reiterando, eso sí, que la Eucaristía no siempre es el tema de los autos, «pero es siempre su motivo».

Para clarificar nuestra exposición, traigamos la definición de misa en el Tesoro de Covarrubias:

Misa: Es el sacrificio incruento del Nuevo Testamento, y ley de gracia, que el sacerdote ofrece, a Dios Padre, de su sacratísimo Hijo Jesucristo Redentor nuestro, en remisión de nuestras culpas y pecados, que comúnmente le definen los teólogos en esta forma: Missa est summum sacrificium, in quo adhibita oblatione, verum Christi corpus consecratur \& usu Sacramenti perficitur. Trae esta definición el padre fray Diego Jiménez, en su Diccionario eclesiástico, y con ella otras muchas cosas curiosas tocantes a esta materia. Este inefable sacramento instituyó el Señor el jueves de la Cena, pridie quam pateretur, y debajo de las especies de pan y vino dio a sus apóstoles su cuerpo y sangre, diciendo las palabras de la consagración: Hoc est, etc. Y en este mismo tiempo los ordenó sacerdotes, diciéndoles: Hoc facite in meam commemorationem, dándoles poder de consagrar y celebrar este tan alto, único y santísimo sacrificio [...]

Queda clara pues la inseparabilidad de sacrificio de la cruz y Eucaristía, porque ese único sacrificio es la prueba -argumento, dice Calderón-del infinito amor de Dios y de su omnipotencia:

SABIDURÍA $\quad$ Y ahora, en la cuestión entrando de tus dudas, considera que esta grande, esta divina, esta admirable, esta inmensa obra que, en el sacrificio

19. Calderón de la Barca, loa de La segunda esposa. 
de la misa, se celebra, de todo el amor de Dios, de toda su Omnipotencia, es argumento y contiene en sí todas sus grandezas desde que el mundo crio hasta que a juzgarle venga 20 .

Así que, al ser la Eucaristía el «tan alto, único y santísimo sacrificio»-incruento- de la crucifixión y muerte de Cristo en el calvario, para comprender el verdadero objetivo de ciertos autos, es obligado revisar su perspectiva teológica junto con su estructuración y realización literarias. He aquí un ejemplo singular.

\section{LA HIDALGA DEL VALLE COMO «AUTO MARIANO»}

Desde Valbuena Prat, se ha generalizado21 la calificación de único «auto mariano» para La hidalga del valle. Y la pregunta obligada es: ¿Esto es cierto?

Prescindimos de los cuatro bloques señalados por la editora moderna del auto; nuestra lectura es distinta.

\section{1. a parte: Hacia la Inmaculada Concepción}

vv. 1-370: Job y David, a la pregunta de Culpa respecto a nacer manchados, reconocen que todos los de las dos primeras leyes, Natural y Escrita, han nacido manchados, pero cada uno de ellos llama la atención sobre alguna excepción; excepción que, curiosamente, Culpa se niega a «argumentar» con ellos.

vv. 371-878: Gracia impide a Culpa atravesar la tercera puerta; le recuerda la profecía. Alegría en el mundo todo porque un ángel ha anunciado a Ana y Joaquín que les va a nacer una niña. Gracia y Amor-Espíritu Santo proclaman: Tota es pulchra, amica mea, macula non est in te. Gracia y Naturaleza entran en la casa (Inmaculada Concepción), quedando fuera Culpa ${ }^{22}$.

20. Calderón de la Barca, Los misterios de la Misa, vv. 125-136.

21. Esta es la nota 14 de la introducción a la edición crítica, p. 23: «Pero queda sin relación con los demás y como tipo de auto exclusivamente mariano La hidalga del valle» (Valbuena, 1924, p. 35); ver también González Ruiz, en su edición de Piezas maestras del teatro teológico español: "Pero hay autos sacramentales, y muy notorios y celebrados, en los cuales ni siquiera existe la apoteosis eucarística. Se trata de autos dedicados a la Santísima Virgen, entre los cuales, acaso, el ejemplo más notorio sea el de La hidalga del valle, de Calderón de la Barca" (pp. 1718). Frutos, en la suya: "Nuestro propósito es presentar un auto sacramental calderoniano solamente mariano, como La Hidalga del valle" (p. 10), "En efecto, La Hidalga del valle es, como se ha dicho, puramente mariano, sin remate eucarístico" (p. 33). Según Balbino Marcos (1981, p. 59) "La Hidalga del Valle es un auto típico y exclusivamente mariano" (p. 59). Elizabeth Teresa Howe (1983, p. 77) tampoco aludió al autógrafo y no se dio cuenta de la alusión a la Eucaristía: "the only Calderonian auto considered exclusively Marian in theme"».

22. En la edición crítica, después de la acotación, se leen estos versos; por su sentido parece que deben ir antes, puesto que son los que representan «teatralmente» la Inmaculada Concepción: Naturaleza y Gracia entran en el mundo (nacimiento de María), mientras Culpa no consigue entrar con ella: «María sin mancha»: 


\section{2. ${ }^{a}$ parte: Redención universal de Cristo}

Culpa reconoce las figuras y sombras (vv. 945-964) y «conjetura» sobre la «puerta cerrada» (vv. 965-972); pero se niega a aceptar una concepción sin Culpa, por privilegio que le dio Dios mismo; en caso contrario, la niña deberá probar su hidalguía.

De acuerdo con nuestra visión estructural del auto, si hablamos estrictamente de la «Inmaculada Concepción de la Virgen María», como nacimiento de la Niña sin culpa-pecado original, dramáticamente hablando, se culmina en el v. 878. Así que debemos preguntarnos: ¿por qué continúa el auto?

Sería, como mínimo, muy osado por nuestra parte, negar que la segunda parte del auto es «de tema mariano»; pero no lo sería menos proclamar que es «estrictamente mariano». Con estilo típico escolástico, distingamos:

-En cuanto que se sigue demostrando una perspectiva teológica de la Inmaculada Concepción sí es «auto mariano»;

-ahora bien, si analizamos detalladamente la segunda parte del auto, comprobamos que su objetivo, precisamente a partir de la objeción «teológica» de Culpa, es demostrar que, pese a nacer sin el pecado original, la Virgen María también fue redimida por la sangre de Cristo; es decir, dejamos la exclusividad temática mariana para proclamar la Redención universal23.

$$
\begin{array}{ll}
\text { CuLPA } & \text { Es vana sofistería } \\
& \text { querer que esta niña humana } \\
\text { de la sangre de Dios goce } & \\
\text { antes que esté derramada (vv. 1365-1368). }
\end{array}
$$

En La hidalga del valle, con maravillosa dramatización de «idea representable», don Pedro Calderón presentó ante el público la redención universal de Cristo: la de los caídos, más la de María, por privilegio especial, exenta de caer, en cumplimiento del protoevangelio:

\begin{tabular}{|c|c|}
\hline AMOR & $\begin{array}{l}\text { Llega, Gracia, porque va } \\
\text { la Culpa a tomar la puerta. }\end{array}$ \\
\hline NATURALEZA & No sé qué me ha suspendido \\
\hline Placer & $\begin{array}{l}\text { Pasmó la Naturaleza } \\
\text { y esperó un poco a la Gracia. }\end{array}$ \\
\hline CULPA & $\begin{array}{l}\text { Naturaleza, ¿qué esperas? } \\
\text { Entra dentro. }\end{array}$ \\
\hline NATURALEZA & Entra conmigo. \\
\hline GRACIA & $\begin{array}{l}\text { Sí haré. } \\
\text { Vanse las dos. (vv. 871-878). }\end{array}$ \\
\hline
\end{tabular}

\section{NIÑA El privilegio que traes} tú misma es, en esta instancia, contra ti, pues dice él mismo,

23. En el caso concreto de María, se realiza de manera preventiva. No es el momento de entrar en el desarrollo histórico del Dogma de la Inmaculada Concepción; pero sí es obligado recordar que la dificultad de compaginar, desde el punto de vista de la reflexión teológica, los dos misterios -Inmaculada Concepción de María y Redención universal de Cristo - fue lo que retrasó la declaración dogmática. 
en misteriosas palabras, que habrá entre ti y la mujer disensiones y batallas hasta que venga a poner los pies sobre tu garganta; ya se ha cumplido, pues piso tu frente sin que tu rabia pueda atreverse a morderme, con ser víbora pisada, porque, en este inmenso valle de lágrimas, soy la hidalga y hidalga de privilegio que de tu pecho me salva (vv. 1433-1448).

Confirma esta dramatización de la «redención universal», como objetivo de la segunda parte del auto, que la conclusión anuncia el próximo nacimiento del Salvador, con el establecimiento de los siete sacramentos, entre los cuales, el Bautismo lavará la mancha original; y la Eucaristía, aumentará la gracia de los redimidos ${ }^{24}$. La hidalga, por su parte, es «llena de gracia»-Madre de Dios- por virtud y amor del Espíritu Santo.

\section{JUAN PÉREZ DE MONTALBÁN: PARA TODOS. PROFECÍA Y ALEGORÍA}

Hay un fragmento que exige nuestra máxima atención respecto a los «cuatro sentidos bíblicos». De su relevancia nos da idea el hecho de que pertenece al dramaturgo Pérez de Montalbán; lo incluyó en el «Quinto día» de su Para todos, unas páginas antes de sus autos Polifemo y Escanderbech:

«De los sentidos de la Sagrada Escritura y modos que hay de explicarla» 25

Por no ser prolijo en materia que tantos han escrito y que el Predicador debe saber y estudiar con mucha diligencia digo brevemente que, según la más común opinión, los sentidos de la Sagrada Escritura son cuatro: Histórico, Tropológico, Alegórico y Anagógico. Histórico es el que nos enseña la verdad de lo que se ha hecho y la fe de la revelación; Tropológico o Moral, el que acomoda para la emienda de la vida, lo que en el Texto sagrado se refiere; Alegórico, el que debajo de lo que se cuenta, encierra la sombra de lo futuro; y Anagógico, el que nos levanta el Entendimiento a las cosas más sagradas, secretas y celestiales. Sírvanos por ejemplo para todos el agua, que según el sentido histórico y literal, significa ese elemento que baña la tierra; según el Tropológico, las tribulaciones, la sabiduría, la prosperidad del mundo, sus deleites y otras cosas semejantes. Según el alegórico, el Bautismo, la Gentilidad, o la gracia del Espíritu Santo; y según el Anagógico, los Ángeles, y también la Bienaventuranza. Todo esto es de san Euquerio. Y así quien quiere saberlo más por menudo, consulte al dicho Santo, a S. Agustín, a S. Gerónimo, a Sixto Senense, a Silvestro, Vázquez, Becano, Valencia y al Angélico Doctor Santo Tomás. 
Como el fragmento se encuentra en el apartado de los «predicadores», podría pensarse dedicado en exclusiva a los oradores, en cuanto a su preparación y, por las páginas siguientes, a las lecturas recomendables para una formación idónea.

Incluso así, debe considerarse imprescindible para el estudio de los autos sacramentales, puesto que, según la definición explícita de Calderón, los autos son «sermones de teología». Y, por si quedara alguna duda, en las pequeñas introducciones-explicaciones del escritor a los autos Polifemo y Escanderbech, indica: «conociendo Montano por las señas exteriores que era ese Auto el de Polifemo, para hacerle más gustoso en su inteligencia, y dar a entender el acierto del poeta en su alegoría, quiso declarar primero su fabula; y dijo desta suerte: Fábula de Polifemo [...]» (fol. 173v).

Y, en el segundo: «advirtiendo que la historia sobre que se fundaba el Auto era la del valiente Escanderbech, quiso como en la Fábula pasada hacer un proemio a su narrado, para que los que no tenían noticia della agradeciesen la propiedad de la alegoría, y así con gusto y atención de los que le escuchaban, dijo [...]» (fol. 184).

Nos hallamos, pues, ante dos autos inspirados, respectivamente, en una fuente mitológica y en otra histórica, cuyos resúmenes realiza personalmente el dramaturgo para que los espectadores puedan comprender y contrastar mejor el edificio levantado sobre esos datos fundamentales; es decir, la «alegoría», sensu bíblico: con otras palabras, y de acuerdo con una expresión frecuente en la época, nos hallamos con una literatura denominada en la época, «versión a lo divino». De los extremos a los que se llegaba con esa adaptación -entiéndase de seguimiento y/o de apartamiento- da suficiente idea el hecho de que, por ejemplo, Ulises, al declarar su nombre al cíclope Polifemo - el Demonio - no se denomina «Nadie», sino «Yo soy»; y, frente a esa afirmación de Dios como ser absoluto ${ }^{26}$, el auto concluye con la muerte del Pastor-Ulises; o sea, lo contrario del mito. Parece suficientemente claro, pues, que buscar en fuentes eruditas de distintas versiones de los mitos, la inspiración de los dramaturgos en su «vuelta a lo divino» de las fuentes documentales no es suficiente; los dramaturgos se veían obligados, en sus traslaciones, a introducir las modificaciones oportunas en las «historias» para acomodarlas al objetivo espiritual perseguido.

Para ello, en un intento de aproximarnos a la entidad completa de los autos sacramentales, parece imprescindible el siguiente fragmento de Pfandl, escrito bajo la inspiración de las seis partes en que se divide la Summa Theologica de santo Tomás de Aquino:

Si prescindimos de su importancia históricocultural, sólo nos queda hoy el aspecto literario de estas creaciones que fueron un tiempo tan vivas y populares. Este valor literario es de dos clases, si no me engaño: dogmático y poético.

SU DOBLE ASPECTO LITERARIO: EL DOGMÁTICO Y EL POÉTICO

26. Entiéndase correctamente el nombre, pues Éxodo 3,14 dice: «Y respondió Dios a Moisés: Yo soy el que soy. Y dijo: Así dirás a los hijos de Israel: Yo soy me ha enviado a vosotros». Montalbán, pensando en la redención, abre paso a la naturaleza humana del Hijo, única posibilidad de morir en la cruz. 


\begin{abstract}
Ya se indicó antes [...] el punto culminante de todo el dogma. (Ver «Prolegómenos»)

[...]

El aspecto poético, al cual nos referimos ahora, exige un estudio más extenso que el dogmático, una consideración y un examen mucho más fundamentado de los detalles, y por ello una disposición y un análisis más minuciosos del asunto. La comedia era un «teatro de diversión para todos», y a este supremo principio sacrificó sin escrúpulo muchas normas clásicas regulares y artísticas en sentido tradicional; los autos sacramentales eran «un teatro de edificación e instrucción para todo el mundo», que no se había de acomodar a ninguna Ars poetica ni a los antiguos modelos, sino a una orientación individual que brotaba de él mismo27.
\end{abstract}

\title{
7. UN EJEMPLO SINGULAR. PSIQUIS Y CUPIDO
}

En su edición crítica del auto -en nuestra humilde opinión, una de las más detalladas de autos de Calderón- los profesores Enrique Rull y Ana Suárez Miramón, olvidados del asunto exclusivo de «auto sacramental calderoniano», se centran en el análisis literal del mito y su aplicación literaria. ¿Cuál es el resultado?

Nuestra visión de la estructura dramática del auto difiere de la propuesta por estos dos grandes calderonistas, en razón del análisis teológico literario completo del texto.

La acción se divide en dos grandes bloques que, curiosamente, se reparten casi aritméticamente de acuerdo con el número de versos (1854):

La primera parte se extiende desde el principio hasta el v. 914, momento en que Edad Tercera, consciente de que su padre la ha abandonado para que muera en los arrecifes deshabitados, lanza maldiciones contra «Mundo enemigo». Poco después, sin embargo, en el mismo parlamento, tales maldiciones devienen deseos de ventura y bienandanza para sus enemigos.

Es obligado detenernos en el análisis de este parlamento de Tercera Edad (vv. 915-963), por cuanto representa, como una especie de vaivén, mirando, con perspectiva mundana - de tejas abajo - las recriminaciones al padre-Mundo; mientras que, en contraposición, con la aplicación de la perspectiva de los sentidos bíblicos a las citas de la Sagrada Escritura, deslumbra la proclamación de la Redención de Cristo -comprensión, perdón y Amor- transformándolas en toda clase de bendiciones ${ }^{28}$ : 
EDAD 3. ${ }^{a}$

Conque, heredando el delito,

hoy, de la Naturaleza

echada del Paraíso,

desde aquí trasunto soy.

Plegue a Dios, Mundo enemigo;

que ya que a diluvios de agua,

te privilegió el pajizo,

verde, rojo arco de paz,

que Dios tremoló, en indicio

de que no había otra vez

de ejecutar su castigo

por agua, sino por fuego;

tan alta suba contigo,

que el fanal de este bajel,

en una estrella encendido,

baje en diluvios de fuego;

con tan fatal precipicio,

que tú, en tus cenizas, seas

la tumba y él obelisco

Mas, (ay de mí!, )para qué

quejas ni llantos repito,

si es darle, para hacer mejor camino,

agua mis ojos, viento mis suspiros?

Mas ¿qué digo?, que no es

haber quedado conmigo

mi Sencillez, si a venganzas

las sinrazones remito.

Plegue a Dios, que favorable siempre el austro, el mar tranquilo, a tan feliz puerto llegues,

que sea, si yo le elijo,

doblando, a Buena-Esperanza,

el cabo, pues ha cabido

todo en ti el de Santa-Fe,

pasando en siempre benigno

rumbo al de la Vera-Cruz,

Hostia y Cáliz, que vecino

verá, al de Santa-María,

San Lucas, en cuyo abrigo

con sus dos bellas esposas,

te admitan, arrepentidos

de ver mis persecuciones,

Gentilismo y Hebraísmo.

Para esto, sí, para esto

será a mis piedades digno;

que lo que ofendida lloro,

lo que aborrecida gimo

te ofrezca, dando en fe de tus alivios,

agua en mis ojos, viento en mis suspiros. 
Los editores, una vez apuntado el detalle de que, inmediatamente después de las maldiciones, la joven parece arrepentirse, sin embargo, dejan sin explicar esta bendición; decisión comprensible, puesto que, con los exclusivos recursos del análisis literario, no es posible explicar el fragmento. Al entender los «nombres propios» como accidentes geográficos concretos -algunos de los cuales, los editores confiesan honestamente no conocer - el paso dramático queda sin sentido, ya que ninguno de ellos corresponde a accidentes físicos de nuestro planeta.

¿Cómo se explica, pues? La teología nos ayuda. El poeta, a través de las palabras de Edad 3.a, anuncia la redención espiritual de Cristo con mediación de la Virgen María. Vayamos por partes:

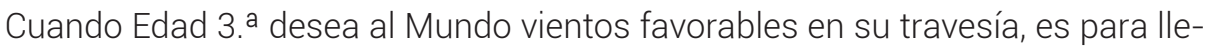
gar a buen puerto; ¿y qué puerto es este? El que, doblando el cabo, con todas las dificultades que ha supuesto, en el transcurso de los siglos, desde la fe de Abrahán, hasta alcanzar la Buena Esperanza; es decir, habiendo llegado la plenitud de los tiempos, la fe da paso - con el cumplimiento de las profecías - a la Buena Esperanza -la redención- culminada en la Vera-Cruz.

Ahora bien, ¿por qué Hostia y Cáliz, que san Lucas verá vecino a Santa María? La respuesta se encuentra en el hecho de que san Lucas es el único evangelista que narra la presentación del Niño Jesús en el templo, momento en que Simeón entona su himno profético de que Cristo será la salvación de su pueblo, pero también será signo de contradicción, y que, en consecuencia, una espada atravesará el corazón de la Virgen ${ }^{29}$.

A mayor abundamiento, en El Maestrazgo del Tusón, un manuscrito ${ }^{30}$ ofrece estas líneas, en bendición de la Esposa hacia la barca de Pedro:

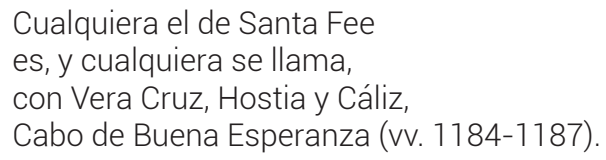

Desde el punto de vista dramático, la primera parte está enmarcada, con la perspectiva y actuación de Odio - reiteración múltiple de «respirando en mí el cierzo de mortal rencor» (vv. 24-25, 50-51, 100-101), que se cierra con el v. 968: «inspirando en mí el cierzo del odio esquivo», y el efecto aterrador del subsiguiente terremoto-. Amor, por el contrario, manifiesta la disposición positiva opuesta a Odio -réplica reiterada de «en mí el aura, inspirando, del Divino Amor» (vv. 26-27) y «respirando

29. «Ahora, Señor, despides a tu siervo en paz, Conforme a tu palabra; Porque han visto mis ojos tu salvación, La cual has preparado en presencia de todos los pueblos; Luz para revelación a los gentiles, Y gloria de tu pueblo Israel. Y José y su madre estaban maravillados de todo lo que se decía de él. Y los bendijo Simeón, y dijo a su madre María: He aquí, éste está puesto para caída y para levantamiento de muchos en Israel, y para señal que será contradicha (y una espada traspasará tu misma alma), para que sean revelados los pensamientos de muchos corazones» (Lucas, 2, 29-35).

30. Se trata del Manuscrito T, del Instituto del Teatro de Barcelona; en nuestra opinión, es el más próximo al original de Calderón. Véase nuestra reseña de la edición de Carlos Castellanos. 
en mí el aura del Divino Amor» (vv. 56-57, 102-103), con el compromiso, para la Tercera Edad, de «el cumplimiento feliz / de aquella gran promisión» (vv. 122-123)-. Y así se lleva a cabo a partir de preguntar la infeliz «tercera hija» abandonada: «¿Hasta cuándo, hados impíos / me afligiréis?» (vv. 984-985), momento en que Amor responde: «Hasta cuando / se muestre el cielo benigno. / Cantando: Inspirando en mí el aura de Amor Divino» (vv. 985-987).

En esta segunda parte, Calderón nos ofrece la dramatización del misterio de la redención del hombre, desde el nacimiento, expresado con el canto de los ángeles en el portal de Belén: «Gloria a Dios en el impirio / y paz al hombre en la tierra» (vV. 1011-1012, 1048-1049, 1098-1099). Que se trata del Verbo encarnado, lo dice explícitamente Amor:

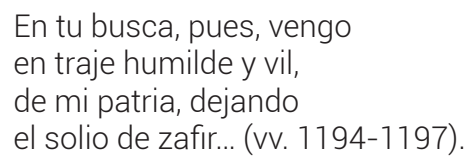

Las reminiscencias del mito de Psiquis y Cupido se hallan, por supuesto, en el ocultamiento de la naturaleza divina de Cristo, pues solo es perceptible el cuerpo humano-mortal; y, sobre todo, en el Sacramento de la Eucaristía -alegorización bíblica de prefiguras veterotestamentarias: espigas de Rut, racimo de Caleb, vino de Canán, maná..., vv. 1288-1291 - instituido, como permanencia constante entre los hombres «debajo de un blanco / velo y un terso viril» (vv. 1268-1269), antes, incluso, de comenzar su pasión en Getsemaní (vv. 1352-1364), y morir en la cruz, condenado por el Hebraísmo y firmada la sentencia por la Gentilidad (vv. 1604-1611).

\section{CONCLUSIÓN}

Para comprender en su exacto sentido los autos sacramentales, sobre todo los de la plenitud creadora de Calderón de la Barca, no basta el imprescindible análisis literario, aun con toda su riqueza y variedad: fuentes clásicas y religiosas, paralelismos, recursos literarios, etc. Es imprescindible añadir la perspectiva de los cuatro sentidos con que, desde los Padres de la Iglesia, se ha estudiado, y se estudia, la Sagrada Escritura.

La identidad «parkeriana» entre argumento y asunto la rechazan teóricamente los diccionarios; en la práctica, distintos autos, especialmente representativo es La divina Filotea. La precisión teológica del único sacrificio de Cristo -cruento, en el calvario; incruento, en la Eucaristía - justifica el valor sacramental de autos como La hidalga del valle, no exclusivamente mariano. La perspectiva teológica completa explica aspectos incomprendidos de la estructura y desarrollo de autos como Psiquis y Cupido.

Tras sucesivos experimentos de sus predecesores, en su Para todos, el autor enuncia la necesidad, al tratar textos bíblicos, de tener presentes los «cuatro sentidos»; y, no conforme con la teoría, incluye, con las aclaraciones pertinentes para 
comprender su alegoría bíblica, los autos Polifemo y Escanderbech. Ahí radica, sin duda, la extraordinaria aportación e importancia de Juan Pérez de Montalbán.

\section{BiBLIOGRAFÍA}

Belda Plans, Juan, La escuela de Salamanca, Madrid, BAC, 2000.

Benedicto XVI, Exhortación Verbum Domini, Roma, 30 de septiembre de 2010.

Calderón de la Barca, Pedro, Autos sacramentales alegóricos y historiales, Madrid, Joseph Fernández de Buendía, 1677.

Calderón de la Barca, Pedro, Amar y ser amado, la divina Filotea, ed. Luis Galván, Pamplona/Kassel, Universidad de Navarra/Edition Reichenberger, 2006.

Calderón de la Barca, Pedro, Lo que va del hombre a Dios, ed. María Luisa Lobato, Pamplona/Kassel, Universidad de Navarra/Edition Reichenberger, 2005.

Calderón de la Barca, Pedro, Los misterios de la Misa, ed. Enrique Duarte, Pamplona/Kassel, Universidad de Navarra/Edition Reichenberger, 2007.

Calderón de la Barca, Pedro, La hidalga del valle, ed. Mary Lorene Thomas, Pamplona/Kassel, Universidad de Navarra/Edition Reichenberger, 2013.

Calderón de la Barca, Pedro, Psiquis y Cupido (Madrid), ed. Enrique Rull y Ana Suárez Miramón, Pamplona/Kassel, Universidad de Navarra/Edition Reichenberger, 2014.

Covarrubias Horozco, Sebastián de, Tesoro de la lengua castellana o española, ed. Ignacio Arellano y Rafael Zafra, Madrid/Frankfurt am Main, Iberoamericana/ Vervuert, 2006.

La Sagrada Escritura en la Iglesia. Actas del Congreso con motivo de la publicación de la Sagrada Biblia, versión de la CEE, ed. Jorge J. Fernández Sangrador y Juan Antonio Mayoral López, Madrid, BAC, 2015.

Mariscal de Gante, Jaime, Los autos sacramentales desde sus orígenes hasta mediados del siglo XVIII. Estudio crítico y bibliográfico de nuestro teatro sacramental en sus relaciones con las costumbres, la literatura dramática y lírica y las ciencias teofilosóficas. Memoria presentada al XXII Congreso Eucarístico Internacional de Madrid, Madrid, Biblioteca Renacimiento/V. Prieto y Comp., editores, 1911.

Parker, Alexander A., Los autos sacramentales de Calderón de la Barca, Barcelona, Ariel, 1983.

Pérez de Montalbán, Juan, Para todos, Madrid, Luis Buendía, 1651.

Pfandl, Ludwig, Historia de la literatura nacional española en la Edad de Oro [1929], traducción Jorge Rubio Balaguer [1933], Barcelona, Gustavo Gili, 1952.

Villanueva, Juan Manuel, El teatro teológico de Mira de Amescua, Madrid, BAC, 2001. 
Villanueva, Juan Manuel, «La taxonomía de los autos y los cuatro sentidos bíblicos: La escuela divina, de José de Valdivielso», Revista Boletín Lengua y Literatura Españolas. FASPE 51, abril-junio 2008, pp. 13-20.

Villanueva, Juan Manuel, «Una lectura complementaria de la introducción al primer volumen de los autos de Calderón», en Teatro y fiesta popular y religiosa, ed. Mariela Insúa y Martina Vinatea Recoba, Pamplona, Servicio de Publicaciones de la Universidad de Navarra/Publicaciones Digitales del GRISO, 2013, pp. 439-455.

Villanueva, Juan Manuel, Uclés, El Escorial de La Mancha. Atalaya del mundo. Historia del seminario menor Santiago Apóstol (Cuenca), Cuenca, Diputación Provincial de Cuenca, 2014.

Villanueva, Juan Manuel, «La alegoría retórica y bíblica en los autos de sor Juana Inés de la Cruz y Calderón. Hacia una revisión de los tópicos de Wardropper, Parker y Valbuena», en Et nunc et semper festa, ed. Carmen Pinillos y José Javier Azanza, Pamplona, EUNSA, 2019, pp. 307-332.

Wardropper, Bruce, Introducción al teatro religioso del Siglo de Oro. La evolución del auto sacramental, 1500-1648, Salamanca, Anaya, 1967 (1. a ed. Madrid, Revista de Occidente, 1953). 